\title{
Corrective Feedback for Learners of Varied Proficiency Levels: A Teacher's Choices
}

Sara Kennedy

This study investigates how one English-as-a-second-language (ESL) teacher provided corrective feedback to 15 child ESL learners that the teacher had divided into two groups based on proficiency level. Classroom data in transcripts from the CHILDES database were analyzed for type of learner errors, type of teacher feedback, and rate of learner uptake (attempts at correction) and repair (correction). Results showed differences in the types of errors produced by each proficiency group and in the type of feedback the teacher provided to each proficiency group, demonstrating provision of finely tuned corrective feedback based on learners' individual differences.

Cette étude porte sur la rétroaction corrective d'un enseignant en ALS avec 15 élèves répartis en deux groupes en fonction de leurs compétences. Des transcriptions de la base de données CHILDES et portant sur des données de salles de classe ont été analysées pour déceler le type d'erreurs chez les apprenants, le type de rétroaction de la part de l'enseignant, et taux d'application (tentatives de se corriger) et de correction par les apprenants. Les résultats révèlent des différences dans le type d'erreurs produites par chaque groupe et dans le type de rétroaction fournie par l'enseignant à chaque groupe, démontrant l'adaptation de la rétroaction corrective aux différences individuelles chez les apprenants.

\section{Introduction}

In 1997 Lyster and Ranta published a seminal article on the use of corrective feedback by teachers in grades 4 and 5 French immersion classrooms. This article presaged a growing body of research on corrective feedback for and by second-language (L2) learners. A basic question underlying-although not altogether resolved by-research on corrective feedback is this: What kinds of feedback for what kinds of errors are effective for what kinds of learners? Lyster and Ranta found that although the French immersion teachers provided corrective feedback for most learners' errors, some types of feedback were more effective than others. One of the possible factors that seems to influence the effectiveness of corrective feedback is L2 learners' level of proficiency (Ammar \& Spada, 2006; Havranek \& Cesnik, 2001; Lin \& Hedgcock, 1996; Mackey \& Philp, 1998). 
Results from studies on corrective feedback and learner proficiency have generated valuable suggestions for L2 teaching. However, these results are based on observation or assessment of multiple groups of learners and teachers or interlocutors. In other words, research on corrective feedback and learner proficiency thus far has largely not targeted individual teachers, or specifically how a teacher may provide feedback to learners of varied proficiency levels in his or her classroom. A notable exception is Lightbown (1991), who remarked on the effectiveness of one L2 teacher's feedback strategies for learners making a particular type of error. Because much corrective feedback provided to classroom L2 learners comes from teachers, ${ }^{1}$ it is important to determine how (and why) individual teachers provide feedback to individual learners and to assess how effective particular types of feedback are for a given learner. Teachers can and do tailor their classroom interactions to address the needs of specific learners. In the current study, I examine a corpus of teacher-student interaction in an English-as-a-secondlanguage (ESL) classroom. I analyze how one teacher adapted his corrective feedback in order to suit learners of varied proficiency levels and how his learners reacted to this feedback. This study thus presents a contextualized picture of corrective feedback in an ESL classroom.

\section{Corrective Feedback and Proficiency Level}

Lyster and Ranta (1997) were among the first to suggest that how teachers choose to provide corrective feedback may be linked to learners' proficiency level. Overall, the most common type of corrective feedback given by the four teachers observed in their study was recasts, which are reformulations of learners' inaccurate utterances that provide the correct form while preserving the learners' original meaning (e.g., You got a new bike last weekend, that's great! in response to I get a new bike last weekend). Teachers seldom gave corrective feedback that did not provide learners with the correct form (e.g., You what a new bike last weekend? as a response to I get a new bike last weekend). In this article, these latter types of feedback are referred to as prompts, the term Lyster currently uses (Lyster, 2004; Lyster \& Mori, 2006). Although recasts were common overall in Lyster and Ranta's study, the behavior of one of the L2 teachers was different. This teacher used recasts much less than the others and used prompts more often. Lyster and Ranta believed that recasts were less effective than prompts at pushing learners to repair (i.e., successfully correct) inaccurate utterances. They suggested that because this teacher had high-proficiency learners with a longer and more intensive exposure to French, the teacher could push them to repair errors themselves.

Subsequent studies also targeted teachers' corrective feedback in relation to learner proficiency level, but also measured learners' longer-term language development. The greater effectiveness of prompts over recasts in improving L2 learners' accuracy was demonstrated in a large-scale study of 
over 200 young English-as-a-foreign-language (EFL) learners in Germany (Havranek \& Cesnik, 2001). Teachers and learners were observed in their classes over a number of weeks; then learners were given class-specific tests that included many of the language items that had received corrective feedback from teachers. The feedback type that most often led to accurate posttest results was prompts. The type that was least effective in bringing about post-test accuracy was recasts that learners did not immediately attempt to correct (i.e., recasts with no uptake). However, these results depended on learners' proficiency level in English. Havranek and Cesnik found that learners of overall higher proficiency received more benefit from corrective feedback (had higher post-test scores) than learners of overall lower proficiency.

Other research suggests that recasts can be effective for learners' language development, but only for high-proficiency learners, with proficiency level operationalized as learners' developmental readiness for a specific grammatical structure. Mackey and Philp (1998) targeted the development of question formation by beginner and low-intermediate adult ESL learners who were paired with adult native speakers (NSs). The learners were placed in one of three kinds of groups: interactor (normal negotiated interaction), intensive recast, and control. After five days of information-gap activities for the first two groups, most of the learners who moved up one stage of question formation were those who had received intensive recasts. However, these learners were developmentally ready to move to a higher stage of question formation. Most of the learners who were developmentally unready to move to the next stage did not progress regardless of whether they heard recasts, participated in negotiated interaction, or received no treatment at all. Mackey and Philp concluded that recasts can help learners to progress in their development in question formation, although this seems to be true only for high-proficiency learners.

The long-term effectiveness of both recasts and prompts was investigated by Ammar and Spada (2006), who tracked the acquisition of possessive determiners (PDs) such as his and her in three classes of grade 6 ESL learners. Each intact class had a teacher who naturally took a particular approach to giving corrective feedback. One teacher mainly used recasts, the second mainly used prompts, and the third provided no corrective feedback (control). Each class underwent four weeks of instruction and practice activities on the accurate use of PDs and then was administered tests on production of PDs. Each class had also been subdivided into low- and high-proficiency PD groups. The high-proficiency learners in both the prompt class and the recast class received similar scores on the tests, but the low-proficiency learners in the prompt class scored significantly higher than did the low-proficiency learners in the recast class. Ammar and Spada concluded that although both recasts and prompts can help learners to improve their accuracy of PD use, 
only learners who are already at a high proficiency level are helped by recasts, whereas both low- and high-proficiency learners benefit from prompts.

The studies described above suggest that the effectiveness of various types of corrective feedback in helping L2 learners to produce more accurate language may depend on learners' proficiency. Recasts, which are common in L2 learners' classroom input, may be less effective for low- than for high-proficiency learners (Ammar \& Spada, 2006; Mackey \& Philp, 1998). Prompts can be effective in pushing development for both high- and lowproficiency learners (Ammar \& Spada) and may be most effective overall (Lyster \& Ranta, 1997; Havranek \& Cesnik, 2001).

\section{The Role of Individual Teachers}

As mentioned above, teachers choose to provide certain kinds of corrective feedback to their learners in particular classroom situations. However, the studies described above do not show how individual teachers' views about their lessons and their learners may affect the type of feedback they provide. The lack of focus on individual teachers' judgments about their classes can be seen in at least two aspects of the earlier studies. The first aspect is in how proficiency has been assessed. In most of the earlier studies, the proficiency level of L2 learners was assessed by means of tests administered by schools or by researchers, targeting either general L2 proficiency (Havranek \& Cesnik, 2001) or learners' production of one particular syntactic structure such as question formation (Mackey \& Philp, 1998). The perceptions of the classroom teachers who had already been teaching and assessing the learners were not taken into account when researchers placed learners at varied levels of proficiency. The second aspect that deemphasizes the role of individual teachers' choices is the scope of the data used to draw conclusions about corrective feedback and teachers' behavior. In the studies described above, the conclusions (e.g., about what kinds of corrective feedback teachers/interlocutors provided, and how effective the feedback was) were largely based on data that were averaged across several teachers or interlocutors. That is, researchers did not focus on how individual teachers provided corrective feedback to their learners or on how effective that feedback was for individual classes.

These two aspects, typical of much corrective feedback research, mean that the role of individual teachers' choices in the context of their own classrooms is minimized. But ultimately, corrective feedback is provided in specific interactions and contexts. Each teacher makes judgments about the language proficiency of his or her learners, and each then chooses consciously or unconsciously how he or she will act in providing corrective feedback to particular learners at particular times. It is important, therefore, to explore how teachers' own perceptions of their learners' proficiency are related to the 
type of corrective feedback they provide and also how their learners react to this feedback. In the current study, I examine how an ESL teacher who had ranked his learners at varied levels of proficiency provided corrective feedback to the learners and how learners at varied proficiency levels responded to this feedback.

\section{Research Questions}

In order to understand better how and why teachers provide corrective feedback to learners of varied proficiency levels and how learners respond to this feedback, three research questions were investigated.

1. How many and what types of errors are produced by child L2 learners of different perceived proficiency levels?

2. How much and what types of corrective feedback does a teacher provide to child L2 learners of different perceived proficiency levels?

3. How often do child L2 learners of different perceived proficiency levels take up a teacher's corrective feedback and repair errors?

\section{Method}

\section{Corpus}

The corpus of data for this study comes from the CHILDES online database (http://childes.psy.cmu.edu). Twelve transcripts originally published by Guthrie and colleagues (Guthrie, 1983, 1984; Guthrie \& Guthrie, 1987) were considered for analysis. The participants recorded in the transcripts were an ESL teacher whose first language (L1) was English and his class of 15 grade 1 ESL learners whose L1 was Cantonese. The school was in a United States city with a large Chinese population. The class was part of a bilingual program, spending half the day with a bilingual Cantonese-English teacher and half with the ESL teacher, who had little experience with Chinese learners and no knowledge of Cantonese. The school was located in a Chinatown community; almost $50 \%$ of the school population spoke a Chinese language as an L1.

Before recording of the lessons began, both teachers at Guthrie's request had evaluated each learner on a four-point scale of oral English proficiency. The ESL teacher had then on his own initiative divided the class into two groups based on his evaluation of their proficiency: a Low group of six learners and a Mid/High group of nine learners. The terms Low and $\mathrm{Mid} / \mathrm{High}$ are not meant to reflect the groups' objectively measured proficiency levels, only the teacher's perceptions of the proficiency levels of the two groups. The teacher worked with these two groups separately, and while he was working with one group, the other had lessons in another room with another teacher. 
The recordings of the lessons span a two-month period. Recordings were made with a Marantz tape-recorder and two Lavalier microphones placed in the middle of the group's table. At each recording session, two research assistants, who were fluent in English, Cantonese, and Mandarin, took field notes and monitored the recording through earphones. Each audiorecording was transcribed by the research assistants, and any utterances in Cantonese were coded as such and translated into English.

\section{Transcripts}

The original 12 transcripts of lessons in the database consisted of oral English work, where the focus was usually on learning or reviewing vocabulary. For vocabulary lessons, the teacher usually used picture flashcards to elicit vocabulary from the learners while everyone sat together at a large table. Of the 12 transcripts available, two each from both groups of learners (4 in total) were of free-talk activities when the learners were engaged in activities at their desks and talking to each other and there was no sustained teacher-student interaction. These transcripts were not considered for the current analysis because the focus of this study was corrective feedback provided by the teacher.

Of the remaining eight transcripts (comprising 9,810 words), which were analyzed, the analysis centered on two types of oral activities: (a) learning or reviewing vocabulary (Vo), and (b) elicitation of personal information (PI) such as addresses. The beginnings of the activities were identified by the teacher's first utterance either telling the students that they would look at pictures (Vo) or asking for personal information (PI). The ends of the activities were identified by the teacher starting an alternate activity or by the end of the transcript. Other activities or talk that occurred (e.g., administrative tasks) were not coded for analysis. Following standard protocol, the last five student turns before the end of the transcript were not analyzed.

\section{Matching of Data}

Of the eight transcripts coded for analysis, three were of the Low group and comprised approximately 38 minutes of oral English lessons. Five transcripts were of the Mid/High group and comprised approximately 105 minutes of oral English lessons. Because of the difference in the number of transcripts and lesson minutes for each group, a straight comparison of absolute numbers of errors, feedback moves, uptake, and repair could not be made. The Mid/High group would almost certainly have higher frequencies in every category simply because more transcripts were available to code. Therefore, it was decided to match the number of student turns that were analyzed from each group's transcripts. This would ensure that one group had not had more opportunity than the other to respond to any feedback provided. 
For each type of activity (Vo and PI), each group's total number of student turns was counted using the MLT (mean length of turn) command in CLAN software (used to edit CHILDES manuscripts and analyze CHILDES transcripts; http://childes.psy.cmu.edu/clan), starting from the first transcript for each group. The group with the lower total number of student turns for each type of activity was identified. Then the same number of student turns was selected from the other group. For Vo activities, the Low group's total of 523 student turns was matched with the first 523 student turns for the Mid/High group. For PI activities, the Mid/High group's total of 203 student turns was matched with the first 203 student turns for the Low group. Therefore, the total number of student turns analyzed for each group was 523 turns for Vo activities and 203 turns for PI activities for a grand total of 726 student turns per group.

\section{Data Analysis}

The data were analyzed using CLAN software. ${ }^{2}$ All CHILDES transcripts use a transcription format that can be analyzed by CLAN for various elements of interest. These transcripts were recoded to reflect the focus of the current analysis, which was errors, teacher feedback moves, and learner responses to feedback. The coding scheme (see Appendix) used categories based on Lyster and Ranta (1997). These categories were originally designed for feedback on learners' errors of form (e.g., grammatical, lexical, phonological, and use of L1). However, the teacher in this study also frequently provided feedback on learners' errors of content. In order to capture this feedback, the categories were expanded to include errors of content as well as errors of form.

Utterances with errors of form were correct in terms of the semantic content produced, but with at least one inaccurately produced form. Utterances with errors of content were accurate in form, but at least some of the semantic content was not correct in that context (see examples of content and form errors below). An error of content could sometimes superficially resemble a lexical error of form. The working definition used to identify content errors was The learner produces an utterance or word which is not similar to the target utterance or word, though potentially appropriate in other contexts, or the learner misunderstands a request or question and answers inappropriately. The inaccuracy of the answer is not due to lack of vocabulary or inaccurate word retrieval. For lexical errors of form the working definition was The learner produces a word that is similar to the target word, or a word that is not similar, but whose referent is clearly the same as the target word. If it was not clear whether an utterance was in fact inaccurate with respect to lexis or content, the utterance was not coded as an error. Excerpts 1 and 2 show examples of content and lexical errors respectively. The content errors in Excerpt 1 are learners' (AHP and $\mathrm{PHU}$ ) inaccurate initial responses to the teacher (LAR) that the animals 
in the picture are all together rather than in separate groups. The lexical error in Excerpt 2 is PHU's initial use of the word mustache instead of whiskers.

(1) LAR: are all the animals all together?

AHP: yeah.

PHU: yeah.

LAR: they all [interrupted]

PHU: no.

LAR: where are some of the animals?

PHU: some right.

PHU: these are some this side.

(2) LAR: dog and cats have them too.

PHU: a mustache.

LAR: it's not called mustache it's called whiskers.

PHU: moochstache.

SEV: whisker

Wherever an error of form or content received feedback, the coding scheme ensured that the error, the teacher's feedback, and the learners' response to the feedback were coded.

(3) LAR: what did you play at home sweetie?

MEO: uh play something.

MEO: play ball.

LAR: you played ball.

MEO: yes.

In Excerpt 3, the teacher (LAR) asked a student who did not go on a field trip what she did at home that day. The learner (MEO) responded that she played ball, but her utterance was ungrammatical. The teacher provided feedback for this grammatical error as a recast, but there was no uptake of the feedback by any learner (i.e., there was no attempt to repair the error that was recast). This sequence of error, teacher feedback, and (lack of) learner response was captured using the coding scheme. However, sometimes errors were produced that did not receive immediate feedback (e.g., see PHU's final utterance in 2). The coding scheme was, therefore, adapted so that errors without feedback could also be counted while an accurate count of feedback and learner response was still preserved.

The FREQ command in CLAN was used to count the frequency of various types of errors, feedback, uptake, and repair for each group of learners. In the transcripts analyzed for each group, the vocabulary activities (Vo), and elicitation of personal information (PI) activities were analyzed separately. The frequency counts presented below show the total frequency of errors, feedback, uptake, and repair for each learner group. The results are presented descriptively. Parametric statistical tests were not conducted because of the small sample size of each learner group $(n<10)$. 


\section{Results}

The first research question targeted the amount and types of errors produced by learners of varied perceived proficiency levels. First, results for content and form errors are presented; then results for various types of form errors are shown.

\section{Content and Form Errors}

Although the total number of errors produced by each group was similar, the general types of errors produced were not. Almost 30\% of the total errors produced by the Low group were errors of content, whereas only $8 \%$ of the errors for the Mid/High group were errors of content. However, whereas the Mid/High group produced $92 \%$ of their errors as errors of form, $71 \%$ of the Low group's total errors were errors of form. Table 1 shows the raw frequencies of content and form errors that correspond to these percentages.

\section{Types of Errors of Form}

The raw frequency of five types of errors of form produced by each group is shown in Table 2. Originally, a sixth category for a turn with multiple types of errors was coded, but the low number of occurrences for this category (4) meant that it could not stand as a category on its own. Therefore, the turns with multiple errors of form were reexamined, and the data were reclassified into other categories. For example, a turn with a lexical and a grammatical error would be reclassified as separate lexical and grammatical errors and added to the frequency counts in those categories. This practice is recommended by Hatch and Lazaraton (1991) when one category of frequency data is low.

Figure 1 shows the raw frequencies of types of errors of form recalculated as percentages of the total error counts. As Figure 1 shows, $21 \%$ of the total errors of form produced by the Mid/High group were lexical errors, whereas only $3 \%$ of errors of form were lexical for the Low group. However, the Low group used the L1 more than did the Mid/High group (13\% to 5\%). Although the Mid/High group produced grammatical errors more frequently than did the Low group (see Table 2), the relative percentage of grammatical

Table 1

Frequency of Errors of Content and Form

\begin{tabular}{lccc}
\hline Group & \multicolumn{2}{c}{ Error type } & Total \\
& Content & Form & \\
\hline Low & 41 & 100 & 141 \\
Mid/High & 12 & 133 & 145 \\
Total & 53 & 233 & 286 \\
\hline
\end{tabular}


Table 2

Frequency and Type of Errors of Form

\begin{tabular}{lrrrcc}
\hline \multirow{2}{*}{ Group } & \multicolumn{4}{c}{ Error type } & \multirow{2}{*}{ Total } \\
& Gram & L1 use & Lexical & Phonological & \\
\hline Low & 69 & 13 & 3 & 16 & 101 \\
Mid/High & 84 & 7 & 29 & 16 & 136 \\
Total & 153 & 20 & 32 & 32 & 237 \\
\hline
\end{tabular}

errors out of total errors produced was slightly higher for the Low group than for the Mid/High group (68\% to $62 \%$ ). The Low group also produced a somewhat higher percentage of errors of form that were phonological than did the Mid/High group (16\% to $12 \%)$.

The second research question targeted the amount and types of corrective feedback the teacher provided to learners of varied perceived proficiency levels. First, the types of feedback examined in the current study are described; then the frequencies and percentages of each type are presented.

Types of Corrective Feedback

Lyster and Ranta (1997) classified feedback types into six categories: recasts, explicit correction, clarification requests, metalinguistic feedback, elicitation, and repetition. ${ }^{3}$ Because there were few to no occurrences for many of these feedback categories (e.g., metalinguistic feedback was provided a total of four times across both groups), the feedback types were collapsed into two categories: either the teacher provided the correct form while giving correc-

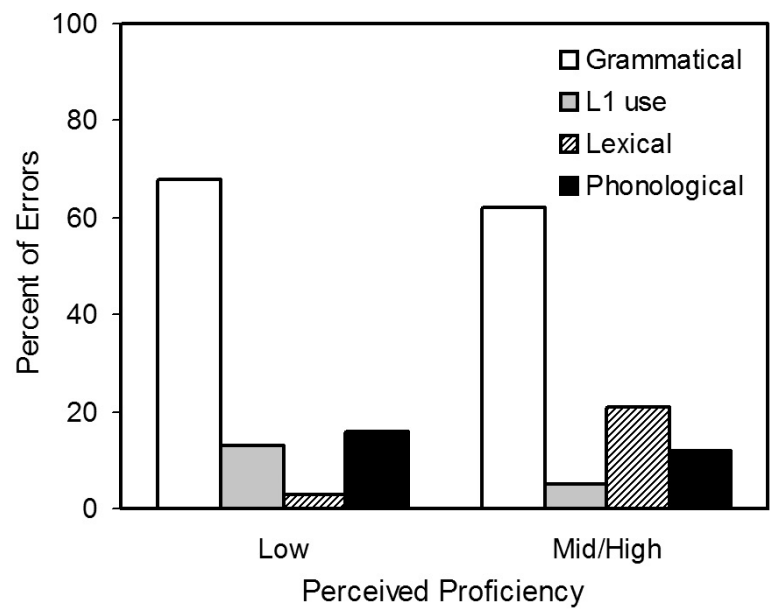

Figure 1. Percent of errors of form according to learners' level of perceived proficiency. 
Table 3

Frequency and Type of Corrective Feedback

\begin{tabular}{lccc}
\hline \multirow{2}{*}{ Group } & \multicolumn{2}{c}{ Type of corrective feedback } & Total \\
& Form provided & Form not provided & \\
\hline Low & 19 & 11 & 30 \\
Mid/High & 9 & 17 & 26 \\
Total & 28 & 28 & 56 \\
\hline
\end{tabular}

tive feedback (explicit correction and recasts), or the teacher did not provide the correct form while giving corrective feedback (clarification requests, metalinguistic feedback, elicitation, and repetitions). The raw frequencies of the two types of corrective feedback are shown in Table 3 and the relative percentages are plotted in Figure 2.

Both groups received similar amounts of total feedback on errors of form. However, the types of feedback received by each group were the inverse of each other. The correct form was included in almost two thirds $(63 \%)$ of the corrective feedback that the teacher provided to the Low group. For the Mid/High group, the correct form was provided in just over one third (35\%) of the corrective feedback given by the teacher; the remainder of the feedback $(65 \%)$ was provided as prompts where the teacher signaled that utterances were inaccurate, but did not provide the correct form.

The third research question targeted the rate of uptake of the teacher's corrective feedback and repair of errors by learners at varied perceived

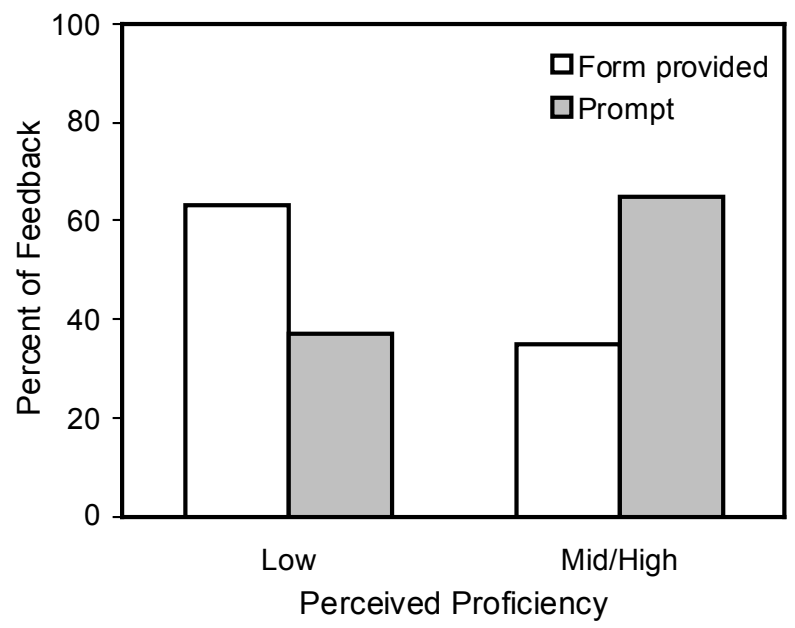

Figure 2. Percent of corrective feedback that provides and does not provide the correct form according to learners' level of perceived proficiency. 
Table 4

Frequency of Uptake Following Feedback on Form

\begin{tabular}{lccc}
\hline & \multicolumn{2}{c}{ Learner response } & \\
Group & Uptake & No uptake & Total \\
\hline Low & 15 & 15 & 30 \\
Mid/High & 19 & 7 & 26 \\
Total & 34 & 22 & \\
\hline
\end{tabular}

proficiency levels. First, results for learners' uptake of feedback (attempt to repair an error in response to feedback) are shown; then results for repair (successful correction) of errors following learner uptake are presented.

\section{Uptake}

The raw frequencies of corrective feedback on form that was or that was not followed by uptake (when learners attempted to repair errors following feedback) are shown in Table 4.

Reported as percentages in Figure 3, the data show that when the Mid/High group received feedback, they usually ( $73 \%$ of the time) responded to it, whereas the Low group did not take up the feedback half $(50 \%)$ of the time.

\section{Repair}

The incidence of repair was low for both groups, but for both groups the patterns of repair somewhat resemble the patterns of uptake. Table 5 shows

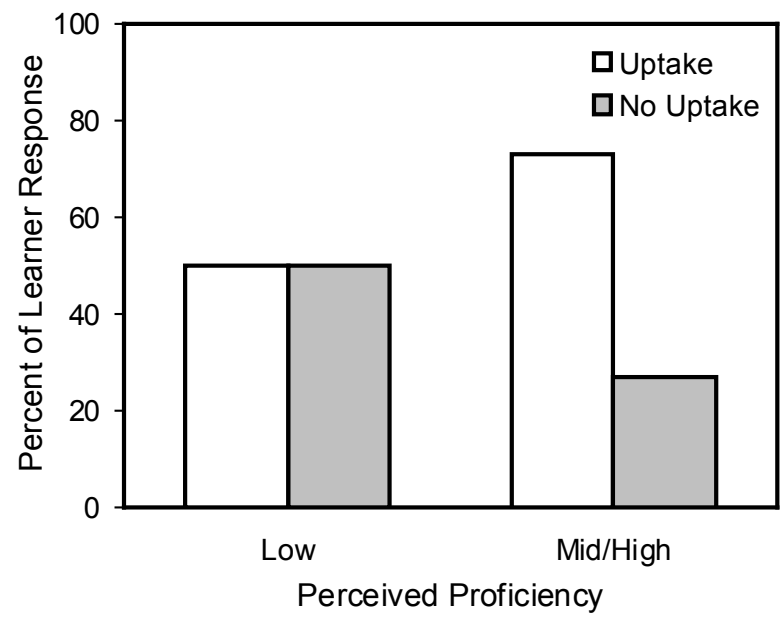

Figure 3. Percent of learner uptake according to learners' level of perceived proficiency. 
Table 5

Frequency of Repair Following Feedback on Form

\begin{tabular}{llcl}
\hline Group & \multicolumn{2}{c}{ Attempted correction } & Total \\
& Repair & No repair & \\
\hline Low & $6(40 \%)$ & $9(60 \%)$ & 15 \\
Mid/High & $10(53 \%)$ & $9(47 \%)$ & 19 \\
Total & 16 & 18 & 34 \\
\hline
\end{tabular}

that the Mid/High group repaired just over half $(53 \%)$ of the corrective feedback moves taken up. The Low group, on the other hand, repaired only $40 \%$ of the feedback moves taken up.

In summary, some discernible patterns in error types and feedback moves were found between the two groups. The Low group produced relatively more content errors than the Mid/High group, who in turn produced relatively more errors of form than the Low group. Of the errors of form, the Low group produced relatively more L1 errors, and the Mid/High group produced relatively more lexical errors. The Low group received relatively more feedback in which the correct form was provided than feedback in which it was not, whereas the opposite was true for the Mid/High group. Although the Mid/High group was not often provided with the correct form, they took up the feedback relatively more often than did the Low group and also repaired errors relatively more often than did the Low group.

\section{Discussion}

This study differs from many earlier studies on corrective feedback in that earlier studies focused on general patterns of corrective feedback, combining data from several teachers and their classes of learners, whereas this study focused on corrective feedback given by one teacher to his class of child L2 learners. The study targeted the amount and type of errors produced by the learners at varied perceived proficiency levels, their teacher's choices in providing feedback in response to their errors, and the learners' responses to the feedback.

\section{Errors}

Although the overall frequency of errors was fairly low, clear differences appeared between the Low and Mid/High proficiency groups. The Low group produced more content errors, whereas the Mid/High group produced more errors of form. These results may be due to weaker abilities of the Low group in understanding oral English, which may have been a factor in their teacher's classifying them as low proficiency. All the grade 1 students probably had had little exposure to English before starting school. 
They lived in a neighborhood with many Chinese residents and may have received most of their exposure to English from television. The Low group may simply have been less able to understand the teacher's questions, as Excerpt 4 shows. The teacher (LAR) had asked about groups of animals, but the learners misinterpreted his question to be about individual animals.

(4) LAR: how many groups of animals do you see?

AHT: [unintelligible]

PHU: I like rabbit(s).

SEV: a one ... two ... three ... four ... five ... six ... seven ... eight ... nine ... ten ... eleven ... twelve.

SEV: OK.

PHU: eleven.

Because the Mid/High group seemed to be more proficient in listening, they misinterpreted fewer of the teacher's questions. This may explain the lesser amount of content errors in the Mid/High group. However, the greater number of errors of form for the Mid/High group seems puzzling. If the Mid/High group was indeed more proficient, why were they producing more errors of form? The answer may lie in the types of questions and prompts that the teacher provided to each group and in the amount of language that each group produced. In Excerpt 5, which is typical of the teacher's interactions with the Low group, the teacher was asking Low group learners to describe a picture in which two mice were walking through a hollowed-out tree. The teacher asked questions (italicized here) that would allow the students to answer despite a low level of proficiency.

(5) LAR: what are these two doing?

AHN: looking.

LAR: they were doing what?

LAR: they're walking where?

PHU: um.

WYM: a circle.

AHN: [unintelligible] four five six seven eight.

LAR: no.

PHU: going around the tree.

LAR: these two mice right in the center.

LAR: they are walking.

Because of the types of questions being asked (They were walking where?), little language needed to be produced to answer the questions, and opportunities for errors of form were reduced. In contrast, the questions that the teacher asked the Mid/High group required more elaborate and creative answers, thus more opportunities to produce errors of form. In Excerpts 6 and 7, which are representative of the teacher's interactions with the Mid/High group, the teacher allowed the Mid/High group learners much 
more freedom in describing objects in the pictures. In Excerpt 6, this object was a tiger.

(6) LAR: tell me about the tiger.

ANT: uh...

MEY: it's got black and....

LAR: black what?

MEY: [unintelligible]

HIE: I can catch it [unintelligible].

LAR: ssh ok.

LAR: go ahead, go on.

MEY: got a black...?

MEY: and...and the....and the...red.

HIE: white.

HIE: and it has got the little ear.

SEV: [giggle].

ANT: baby ears.

LAR: ssh.

MEY: it has got a mouth and got a tail, got a ...

In Excerpt 7, the teacher showed the learners a picture of a watch, but soon asked them to describe a slightly different object.

(7) LAR: what do you use this for?

STE: to watch the time.

HIE: tell time.

STE: what time is it?

LAR: ok.

STE: and tell time.

LAR: ok.

LAR: you can speak louder.

STE: and tell people.

CHR: you wear on your wrist.

LAR: tell me about a blind person's wristwatch

LAR: Steven.

STE: they have a dot in it.

ANT: dot.

STE: a dot. a little dot.

The greater freedom given to the learners in the Mid/High group to make their own decisions on what to say and how to say it also created more opportunity for errors of form, including grammar and lexis, to arise. As well, the learners in the Mid/High group were more willing to make comments, elaborate on, or repair others' answers. For example, HIE's answer in Excerpt 7 repaired STE's lexical error. In contrast, the learners in the Low group mostly elaborated on other learners' answers in their first language, which led to a greater amount of L1 errors. 


\section{Feedback}

The types of form-focused feedback received by the two groups also varied, which is noteworthy in the light of findings by Mackey and Philp (1998) and Ammar and Spada (2006). They found that lower-proficiency learners could not use recasts to further their L2 development on particular linguistic features, whereas higher-proficiency learners could. However, in the current study, the Low group received more feedback in which the correct form was provided (recasts fall under this category), whereas the Mid/High group received more feedback in which the form was not provided. The difference probably reflected the teacher's belief that the Mid/High group had more linguistic resources to draw on if they received feedback simply that the form of their utterances was inaccurate. Because this group was better able to repair their errors, they were given more opportunity to do so (see Lyster \& Ranta, 1997, for a similar explanation).

For the Low group, who may not have had as much knowledge about English at their disposal, the teacher provided more feedback in which the repair work was already done (i.e., the correct form was provided, as in a recast). The feedback may have also served as models to provide more input to the students on how such utterances are accurately produced. Of the 19 feedback moves to the Low group in which the correct form was provided, 15 moves were recasts. Twelve of the 15 recasts were full recasts where the teacher provided the recast in a full utterance (e.g., It has got little ears) as opposed to an isolated utterance (e.g., little ears). For learners at low proficiency, locating a repaired error in a full recast would be a heavy task. This suggests that the teacher, who perceived the learners to be at a low level of proficiency, was using recasts more as models than as corrective feedback. This use of feedback for non-corrective purposes led Lyster and Mori (2006) to refer to "interactional feedback" rather than "corrective feedback" in order to include feedback that does not necessarily have a corrective function.

\section{Uptake and Repair}

The perceived higher proficiency level of the Mid/High learners seemed to be borne out in their higher rate of uptake of the teacher's corrective feedback than in the Low group. This greater percentage of uptake by the Mid/High group may have had several sources. One reason may simply have been their greater ability to understand oral English and thus to understand that the teacher's utterance was meant to be corrective. Another reason may have been that the Mid/High group had more linguistic resources to call on than did the Low group, so that the Mid/High group could more frequently use those resources to attempt to repair their utterances. Yet another reason may have been that the corrective feedback received by the Mid/High group was simply more conducive to uptake than the feedback received by the Low group. Mackey and Philp (1998) and others (Braidi, 2002; Gass, 1997) have 
suggested that in interactions between speakers, uptake following corrective feedback and especially following recasts may sometimes be inappropriate or impossible. When teachers recast learners' utterances, they may sometimes simply continue with their turn, not allowing learners the chance to respond and attempt to repair the error (e.g., It has got little ears, that's right. What else does it have?). However, when teachers use prompts, there is usually more opportunity for learners to respond to the feedback because the correct form has not been provided (e.g., It has got what?). Most of the corrective feedback received by the Mid/High group did not have the correct form provided, whereas most of the corrective feedback received by the Low group did provide the correct form. The Mid/High group may have taken up feedback more often because it was appropriate and they were expected to do so.

The final difference between the two groups was in the rate of repair (successful correction) of errors of form that had been taken up. The total number of errors of form that were repaired overall was low, less than $10 \%$ for either group. For those errors that had been taken up in each group, the Mid/High group repaired a higher percentage than did the Low group, although the Mid/High group repaired only just over half the errors to which they responded. The generally low rate of repair is no doubt because both groups had recently started to learn English. Like their higher rate of uptake, the Mid/High group's higher rate of repair may be due to their having greater linguistic resources for correcting utterances than the Low group, or due to having more opportunities to repair utterances because of the type of corrective feedback (prompts) that was usually provided. Because the number of errors that were both taken up and repaired was low for both groups, it would be desirable in future to see if L2 lessons with more occurrences of uptake and repair show patterns of results resembling those presented here.

\section{Corrective Feedback and Individual Teachers}

This study is, of course, limited by the amount of classroom interaction that could be analyzed. Nevertheless, the results are telling. It is clear that for this individual teacher, his perceptions of his learners' proficiency levels reflected the various types of errors made by his learners. It is also clear that the teacher adapted the type of feedback that he provided to suit learners at varied levels of perceived proficiency. Much corrective feedback takes place in interactions between individual teachers and their learners. As demonstrated in this study, the choices that teachers make in providing feedback are affected by their understanding and assessment of their learners. However, in order to gain a more comprehensive picture of how and why individual teachers provide feedback to their learners, further investigations using larger corpora of lessons from individual teachers are necessary. These 
investigations might include not only discourse analysis of classroom interactions, but also teacher and learner interviews or retrospection about their teaching and learning styles and their intentions and preferences in providing or receiving feedback, as well as assessment of learners' long-term language development. Mackey et al. (2007), for example, observed individual L2 teachers providing feedback to their classroom learners and then elicited the teachers' intentions and learners' perceptions of specific feedback episodes, although the researchers did not assess how learners' language developed in each class. Teachers have reasons for doing what they do in their classrooms. It remains to give them the opportunity to explain and reflect on their behavior and to evaluate its long-term effects for their learners.

\section{Notes}

${ }^{1}$ Considerable research on corrective feedback is provided by L2 learners to L2 learners (peer feedback). The focus of this article is corrective feedback provided by the teacher, but the reader is referred to Adams (2007) for a discussion of research on peer corrective feedback.

${ }^{2} \mathrm{~A}$ reviewer suggested that a qualitative analysis of the data would be productive. Qualitative analyses (e.g., classroom ethnographies, retrospective interviews) do indeed provide rich information about the learning context and teachers' beliefs and decisions, as shown in Basturkmen, Loewen, and Ellis $(2004)$ and Borg $(1999,2003)$. The data from CHILDES analyzed in the current study comprised transcripts of spoken interaction in the classroom. No ethnographic notes, interviews, or similar data were available for qualitative analysis. In future studies of teachers' feedback choices, a mix of both qualitative and quantitative analyses would be beneficial.

${ }^{3}$ Lyster and Ranta (1997, pp. 46-48) give the following definitions of these feedback types: "Explicit correction involves the explicit provision of the correct form ... Recasts involve the teacher's reformulation of all or part of a student's utterance, minus the error ... Clarification requests ... indicate to students either that there utterance has been misunderstood by the teacher or that the utterance is ill-formed in some way and that a repetition or reformulation is required ... Metalinguistic feedback contains either comments, information, or questions related to the well-formedness of the student's utterance, without explicitly providing the correct form ... Elicitation refers to ... techniques that teachers use to directly elicit the correct form from the student ... Repetition refers to the teacher's repetition, in isolation, of the student's erroneous utterance" (pp. 46-48).

\section{Acknowledgments}

The author gratefully acknowledges Yuriko Oshima-Takane for her help with CLAN coding and analyses of CHILDES data, Hirohide Mori and Randall Halter for their advice on research design and data analysis, and Pavel Trofimovich and two anonymous reviewers for their feedback on earlier drafts of this article. An earlier version of this articles was presented at the 2005 Conference of the Canadian Association of Applied Linguistics/Association canadienne de linguistique appliquée.

\section{The Author}

Sara Kennedy is an assistant professor in the Department of Education at Concordia University. Her research focuses on the intelligibility of second-language speaking ability, particularly on how intelligibility is taught and evaluated. She has extensive experience teaching English as a second and foreign language. 


\section{References}

Adams, R. (2007). Do second language learners benefit from interacting with each other? In A. Mackey (Ed.), Conversational interaction in second language acquisition (pp. 29-51). Oxford, UK: Oxford University Press.

Ammar, A., \& Spada, N. (2006). One size fits all? Recasts, prompts, and L2 learning. Studies in Second Language Acquisition, 28, 543-574.

Basturkmen, H., Loewen, S., \& Ellis, R. (2004). Teachers' stated beliefs about incidental focus on form and their classroom practices. Applied Linguistics, 25, 243-272.

Borg, S. (1999). Teachers' theories in grammar teaching. ELT Journal, 53, 157-167.

Borg, S. (2003). Teacher cognition in grammar teaching: A literature review. Language Awareness, 12(2), 96-108.

Braidi, S.M. (2002). Reexamining the role of recasts in native-speaker/nonnative-speaker interactions. Language Learning, 52(1), 1-42.

Gass, S.M. (1997). Input, interaction, and the second language learner. Mahwah, NJ: Erlbaum.

Guthrie, L.F. (1983). Learning to use a new language: Language functions and use by first grade Chinese-Americans. Oakland, CA: ARC Associates.

Guthrie, L.F. (1984). Contrasts in teachers' language use in a Chinese-English bilingual classroom. In J. Handscombe, R.A. Orem, \& B.P. Taylor (Eds.), On TESOL '83: The question of control (pp. 39-52). Washington, DC: TESOL.

Guthrie, L.F., \& Guthrie, G.P. (1987). Teacher language use in a Chinese bilingual classroom. In S.R. Goldman \& H.T. Trueba (Eds.), Becoming literate in English as a second language (pp. 205-231). Norwood, NJ: Ablex.

Hatch, E., \& Lazaraton, A. (1991). The research manual: Design and statistics for applied linguistics. Boston, MA: Heinle and Heinle.

Havranek, G., \& Cesnik, H. (2001). Factors affecting the success of corrective feedback. Eurosla Yearbook, 1(1), 99-122.

Lightbown, P.M. (1991). What have we here? Some observations on the role of instruction in second language acquisition. In R. Phillipson, E. Kellerman, L. Selinker, M. Sharwood Smith, \& M. Swain (Eds.), Foreign/second language pedagogy research: A commemorative volume for Claus Faerch (pp. 197-212. Clevedon, UK: Multilingual Matters.

Lin, Y., \& Hedgcock, J. (1996). Negative feedback incorporation among high-proficiency and low-proficiency Chinese-speaking learners of Spanish. Language Learning, 46, 567-611.

Lyster, R. (2004). Differential effects of prompts and recasts in form-focused instruction. Studies in Second Language Acquisition, 26, 399-432.

Lyster, R., \& Mori, H. (2006). Interactional feedback and instructional counterbalance. Studies in Second Language Acquisition, 28, 269-300.

Lyster, R., \& Ranta, L (1997). Corrective feedback and learner uptake: Negotiation of form in communicative classrooms. Studies in Second Language Acquisition, 19, 37-66.

Mackey, A., \& Philp, J. (1998). Conversational interaction and second language development: Recasts, responses, and red herrings? Modern Language Journal, 82, 338-356.

Mackey, A., Al-Khalil, M., Atanassova, G., Hama, M., Logan-Terry, A., \& Nakatsukas, K. (2007). Teachers' intentions and learners' perceptions about corrective feedback in the L2 classroom. Innovation in Language Learning and Teaching, 1(1), 129-152. 


\section{Appendix \\ Coding Scheme and Examples}

Descriptions of Category Codes

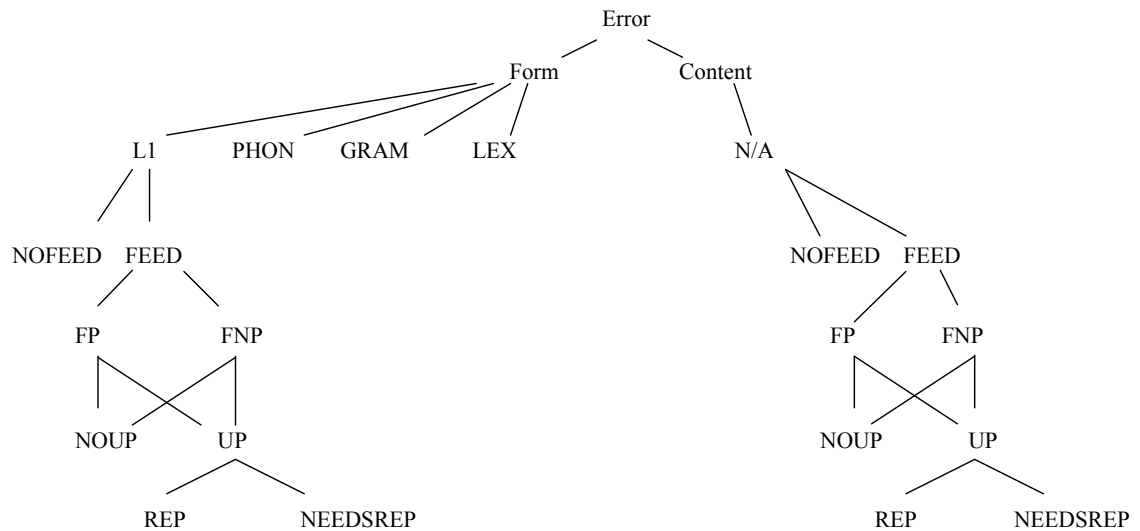

Six hierarchical category levels, showing possible corrective feedback sequences.

Feedback sequences are shown only for $L 1$ and content errors, same sequences apply to other form errors (PHON, GRAM, LEX).

Only one option can be selected at each category level.

Solid lines represent possible paths for corrective feedback sequences.

\section{Errors of Form}

L1

Use of first language

PHON Phonological inaccuracy

GRAM Grammatical inaccuracy

LEX Lexical inaccuracy

Error treatment

NOFEED Teacher does not provide corrective feedback

FEED Teacher provides corrective feedback

Corrective feedback

FP $\quad$ Teacher supplies correct form in corrective feedback

FNP Teacher does not supply correct form in corrective feedback

Learner response

NOUP Learner does not attempt to repair error

UP Learner attempts to repair error

Attempted error correction

REP Learner repairs error successfully

NEEDSREP Learner does not repair error successfully

\section{Errors of Content}

N/A Not applicable (placeholder category to ensure that the same categories are at the same hierarchical levels) 